\title{
AL PIE DEL CAÑÓN POR LA IGLESIA Y EL PERÚ Entrevista a monseñor Hugo Garaycoa Hawkins
}

\author{
José Antonio Benito* \\ Universidad Católica Sedes Sapientiae
}

Resumen: En esta entrevista monseñor Hugo Garaycoa Hawkins nos habla de su labor pastoral, su labor académica, la docencia universitaria y su experiencia en el Concilio Vaticano II.

Monseñor Garaycoa nació el 2 de junio de 1930 en el Callao. Se ordenó de sacerdote el 9 de julio de 1961 y fue consagrado obispo el 25 de enero de 1983. Fue Presidente de la Conferencia Episcopal del Perú. En la actualidad es miembro del Consejo Nacional de Educación.

La Iglesia del Perú celebró de modo muy sentido sus bodas de oro sacerdotales el 9 de junio del 2011. Es coordinador del Diplomado de Doctrina Social de la Iglesia de la Universidad Católica Sedes Sapientiae.

* José Antonio Benito Rodríguez es doctor en Historia de América por la Universidad de Valladolid (Espańa) y diplomado en Educación por la Universidad de Salamanca (España). Es Miembro Ordinario de la Asociación Española de Americanistas, de la sección de Historia del Instituto Riva-Agüero de la PUCP y de la Academia Peruana de Historia de la Iglesia.

Es docente principal de la Universidad Católica Sedes Sapientiae (UCSS), profesor asociado de la Facultad de Teología Pontificia y Civil de Lima y profesor de la Facultad de Teología Redemptoris Mater (Callao, Lima). Es director del Centro de Estudios del Patrimonio Cultural (CEPAC) de la UCSS y Director del Instituto de Estudios Toribianos. Es conductor del programa de televisión El Puente, transmitido por el canal católico PAX TV. Ha publicado numerosas investigaciones en volúmenes y revistas nacionales e internacionales; es un reconocido conferencista en el Perú y en el extranjero. 
Palabras clave: Hugo Garaycoa, Concilio Vaticano II, Conferencia Episcopal del Perú, educación, Iglesia Católica, Doctrina Social de la Iglesia

AвSTRACT: In this interview Monsignor Hugo Garaycoa Hawkins gives testimony of his pastoral work, his academic duties, his university teaching and his experience in the Second Vatican Council. Monsignor Garaycoa was born on June 2, 1930, Callao. He was ordained as a priest on July 9, 1961 and as a bishop on January 25, 1983. He was President of the Episcopal Conference in Peru. Currently, Monsignor Garaycoa is a member of the National Education Council. The Catholic Peruvian Church celebrated his golden jubilee of priesthood on June 9, 2011. Monsignor Garaycoa is the coordinator of the Diploma of Social Doctrine at Universidad Católica Sedes Sapientiae.

Kerwords: Hugo Garaycoa, Second Vatican Council, Episcopal Conference of Peru, education, Catholic Church Social Doctrine of the Church.

Es una alegría enorme poder recibir a monseñor Hugo Garaycoa que, a pesar de estar jubilado —entre comillas - no para, y le agradecemos que haya tenido este paréntesis en su vida tan dinámica para dedicarla también a nosotros, ya que no tenemos la suerte de contar con su sapiencia, como nuestros amigos de Lurin y del diplomado de Doctrina Social de la Iglesia de la Universidad Católica Sedes Sapientiae, por decir dos de los detalles que ahora, en su jubilación, él sigue apuntando como servicio a la Iglesia.

Monseñor Hugo aqui está su casa; bienvenido y muchisimas gracias. 
Gracias por la invitación. En realidad no me gusta hablar de mí mismo, pero si es por algo que le sirva a los demás lo que ha sido la vida de alguien que descubrió al Señor; no que lo descubrió, sino que el Señor le fue haciendo un camino, casi diría un corralito y que puso personas en mi camino que me ayudaron a cambiar de vida totalmente.

\section{Del colegio La Salle a la Universidad Nacional de Ingeniería...}

Sí, a una edad temprana. Salí del colegio a los catorce años, porque quería ser ingeniero mecánico. Había oído hablar que esa carrera era muy remunerativa. De hecho, el ingeniero que fue a dar la charla al colegio decía que esa carrera iba a dar mucho dinero en el futuro, a pesar de que recién comenzaba la ingeniería mecánica; y para mí, fue la palabra mágica, así que decidí ser ingeniero mecánico. Llegué a la UNI, entre y salí.

Pero, ¿cuánto tiempo duró?

Seis meses, me aburrí, ya que no era lo que a mí me gustaba, pero me acordé de un dicho que dice: «el diploma es el disfraz con el que se cubre la ignorancia», y entonces dije: «yo, toda mi vida empleado no voy a ser, quiero tener un diploma». Y me volví a meter a estudiar y entré en el examen de ingreso de la Pontificia Universidad Católica, y allí comencé a estudiar algo que podía compartir entre los estudios y el trabajo que yo tenía en la casa W.R. GRACE CO, en ese entonces.

\section{¿Estudió Economía?}

Contabilidad y Economía, y allí comenzó el Señor a trabajar la cosa. Comencé por salirme de la casa GRACE por una invitación que me hicieron para un trabajo en los laboratorios SQUIBB y triplique mi sueldo en el paso de un lado a otro; no es por nada pero ganaba muy bien. 
¿Los negocios, eh?

Me permitía el lujo de tener un carro, una enamorada, poder ir a una discoteca con la enamorada y las dos hermanas. En ese entonces no le dejaban salir a la chica sola, tenía que ir acompañada y más si era a una discoteca, pero como la hermana, tenía hermanas gemelas, entonces tuve que lidiar con las dos hermanas y ellas dos tenían a la vez su par de enamorados que eran estudiantes, pero rangalidos, porque no tenían dinero para pagar el taxi; pero, bueno, quería divertirme un rato. No era el de los que se emborrachaban no, sino íbamos temprano y salíamos temprano, pero con ella comenzamos un poco aquello que me pidió, que para su cumpleańos la acompañara a la misa y comulgara.

\section{¿Usted practicaba en ese tiempo?}

No practicaba, me había educado en el colegio, pero había salido harto de las misas; no quería saber nada de misas, pero allí fue alguna primera cosa ๙ิ que me presentó el Señor. Después encontré un grupo al que fui un sábado, una meditación sobre el buen samaritano me marcó profundamente.

\section{Usted habla de monseñor Orbegozo.}

Bueno, quien me llevó allí fue un catedrático joven que hoy día es monseñor Luis Sánchez Moreno, y luego la meditación la dio el padre Orbegozo, que era sacerdote simplemente y me impresionó tanto que comencé a ir los fines de semana allá; pero este compañero mío que yo considero instrumento del Señor, me invitó a ir a Huaral a recibir a un padre que llegaba, me reservo el nombre, porque ha dejado de ser sacerdote, pero verdaderamente para mí ese hombre fue modelo de sacerdocio. Preparamos la casa para recibirlo, 
tuvimos que pintarla y arreglarla. Yo nunca había gastado un centavo en nada, la plata era para mí.

\section{Yel tiempo que tuvo que dedicar.}

Y entonces cuando llegó el padre, miró la casa y le gustó, a pesar de que era una casa horrible como para quitar la vocación a uno. Todas las paredes descascaradas y sucias, lo único que había era una cama y el catre era de fierro, con una pata doblada, no había baño, eran dos tablas en un hueco. Luego llegó el padre y vio la casa pintada, limpia y dijo: «iqué linda mi casita!». Yo sentí por primera vez algo en mi corazón, un zamacón muy fuerte, entonces el padre se aprovechó de las circunstancias y me dijo: « ¿ por qué no vienes los sábados para conversar con los jóvenes de la parroquia?».

Yo me comprometí y asistieron varios jóvenes, diez, veinte, treinta, cuarenta y cincuenta jóvenes. Y un día que estaba hablando con los jóvenes, oigo una voz que pregunta: «¿Y el señor Hugo dónde está?», el párroco le contesta y le dice: "El padre Hugo está en el salón del fondo». A mí me ardió, me dolió, me molestó simplemente, y le dije a los chicos con mucha calma: «muchachos, no nos volvemos a ver, jadiós!». Y salí.

¿Se puso bravo el padre?

No, el padre vino y le dije: «padre, ¿con qué derecho usted me toma el pelo? Cura yo jamás, nunca». Me fui y no regresé a Huaral. Pasó un día, otro y otro, pero tenía algo adentro. Entonces, le dije a mi amigo Pedro: «Búscame un sacerdote joven para hablar con él». En ese entonces me trajo al padre Harold Griffiths Escardó. 
Estuvo de capellán en la Universidad de Lima...

Yo le dije: «mira, Pedro, este no sabe nada, búscame a otro mayor», y me llevó al ya difunto monseńor Abarca que era canónigo. Yo hablé con él y también me dijo que sí podría tener vocación. Le dije que no sabía nada. «Pedro, búscame otro». Me buscó al que en ese entonces era el padre Eduardo Picher, tendría más o menos sus cuarenta años o treinta y ocho, pintaba ya un poquito de canas. Y comencé a hablar con él y me dijo: «mira, te digo una cosa: si quieres que yo te ayude, se sincero; si me estas mintiendo como para llevarme a una respuesta, yo no quiero eso». Y fui sincero y comencé a hablar, me dijo que tendríamos que comenzar por un itinerario para ir viendo qué es lo que pasa. Comenzamos el itinerario y lo corté.

Llegó el trece de Agosto de 1954, entonces tomé la decisión de entrar al seminario, estaba dando mi examen de grado y entonces dije: «me gradúo y me voy al seminario». Efectivamente, ingresé en el año 1956; para esto estuve ayudando en lo que era el Congreso Eucarístico Mariano, y el 13 ब de Agosto de 1955 me gradué. Me acuerdo porque el 15 de agosto le dije a mi enamorada que terminábamos porque pensaba entrar al seminario. Me encontré con el cardenal Landázuri, que en ese entonces era vicario capitular y me dice:

- Señor Garaycoa, le espero en mi casa a las cuatro para que tomemos un tecito y hablemos.

Llegué a su casa a las cuatro para tomar el té, y lo primero que me pregunta el cardenal es...

—Oiga, dígame, pues, de una vez... 
— ¿Qué quiere que le diga? ¿Si estoy pensando en el sacerdocio?

—No se hable más. Fidel, prepara el carro que nos vamos al seminario.

Entonces me metió al carro, llegamos al seminario y me presentó al rector. Le dijo: «Normalmente, nosotros conocemos a los candidatos y se lo presentamos al Arzobispo. Aquí ya que usted nos lo trae no hay otro recurso que aceptarlo». Y así ingresé, pero eso fue un jueves, el sábado fui a la reunión, esa famosa y al entrar, el sacerdote que nos atendía, don Manuel Mota, que en paz descanse, me dijo:

-Tengo algo que decirte.

-Yo, también.

Para esto, en esas reuniones conocí también a Armando Nieto, laico todavía en ese entonces y, bueno, al terminar la meditación, le digo

-Padre, ¿qué tiene que decirme?

-No, dime primero tú, qué tienes que decirme.

-Que estoy con el arzobispo y me voy al seminario. Y usted, ¿qué tiene que decirme?

-Te lo diré algún día y no ahora.

Entré al seminario, me adelantaron estudios. Finalmente, después de unas «torturas» de parte del rector conmigo, me enviaron a Canadá a terminar Teología, con unas angustias y unas agitaciones porque yo no hablaba idiomas. 
¿En qué idioma, francés?

Francés. Irme a un lugar desconocido sin hablar el idioma, entendía solo algunas cosas, ya que nos enseñan muy poco de este idioma en el seminario de Lima. Y, bueno, llegué allá, terminé mi Teología, gracias a Dios; luego el Obispo me ofreció una beca en la universidad de La Salle y me pidió que me quedara allá con él. Le escribí al cardenal y me dijo: «muy bien y acepta la beca, pero vienes a ordenarte a Lima». Y así fue, vine a ordenarme a Lima, después de haberme ordenado de diácono allá. Y lo más curioso fue que la primera vez que di la comunión como diácono fue en México, en la iglesia Pedregal. Llegué a Lima y el 9 de julio de 1961, a las 11:35 de la mañana me ordenaban de sacerdote. La noche anterior yo recordé algo que siempre había sońado de chico: «ser caballero de armadura y casco» con todas esas cosas. Y puse mi casulla encima de la cama, y dije: «mañana voy a ser armado caballero». Tengo en mi escritorio ahora tres estatuas de tres caballeros, con espada en mano, para recordarme que fui armado caballero para servir a un solo Señor.

¿Y la dama?

Esa después. Y dije: «me consagro a servir a un solo Señor y a amar a una sola dama, mi madre Santa María». Y por eso llevo una medalla todo el tiempo.

¿Qué advocación es?

La Virgen del Carmen, la medalla escapulario, en realidad. Me ordenaron el 9 de julio por petición expresa mía y me ordené solo, en el seminario de Santo Toribio; lo curioso es que nunca recibí órdenes menores, ni tonsura 
en el seminario, fue la primera vez, ya que todo lo recibí en diferentes sitios, por ejemplo sitios inverosímiles como el cerro San Cosme, el que quedaba por atrás de Dos de mayo, la tonsura en el Palacio arzobispal.

Dios le va preparando para luego ser un obispo en su terreno

Puede ser que sea eso ¿no? Yo siempre lo he pensado. Me ordenaron y me fui a visitar a mis parientes en el norte, en Chiclayo, allí celebré mi primer bautizo, en la capilla de La Soledad, luego pasé a Piura. Yo tenía facultades en Canadá, pero no en Lima y el Obispo de ese entonces me dice: «mira, necesitamos que confieses porque hay muchos niños para confesar en la catedral; así que te doy facultades para que puedas confesar» o sea la primera comunión allá en México, el bautismo, las primeras confesiones, todo repartido por todos lados. Después, siempre me pregunté qué quiere el Señor con esto. El primer matrimonio lo celebré en Italia, la primera unción de los enfermos en la parroquia de San Tomás Fisher en Kent (Inglaterra) y la primera confirmación fue en Lima, por eso yo digo «ibueno!, algo querría decir el Señor, que no iba a estar fijo en un sitio». Pasó el tiempo, y, después de estudiar unos años, regresé de Roma.

¿Hizo en Roma el doctorado?

Sí, allí hice el doctorado en Derecho Canónico, la licenciatura en Derecho Romano y peritaje en Espiritualidad

¿Cuantos años estuvo allá?

Cuatro años y medio. 
¿Y lo aprovechó bien?

Me costó trabajo convencer al Cardenal, primero que me dejara estudiar Derecho Romano, al tiempo que cursaba Derecho Canónico y Espiritualidad. Y, efectivamente, terminé en junio y llevé y me presenté al cardenal el 23 de diciembre con mis tres diplomas. El cardenal ni los abrió; los retiró con su mano al costado. Me dolió terriblemente. El cardenal me miró simplemente y me dijo: «El 31 en la tarde estás entrando al Hospital del Empleado a trabajar». ¡Bueno!, qué vamos a hacer, sin vacaciones, sin haber estado con mi familia...Y Yallí fui por obediencia, al Hospital del Empleado. ¡Maravillosa experiencia! Nueve o diez meses después el cardenal me llama y me dice: «¿estás contento, Hugo?». «Sí, Eminencia, estoy contento». «Bueno, te voy a cambiar». Y cada vez que me hacía un cambio, el cardenal siempre me formulaba la misma pregunta: «¿estás contento, Hugo? Te voy a cambiar». Y siempre le dije «sí», porque yo no juré obediencia, yo prometí no decir nunca no a lo que me pidieran mis superiores.

Háblenos de su labor como docente en la PUCP

Allí daba el curso Derecho Romano I-II

¿Qué alumno recuerda?

Alan García (el presidente), los Bedoya, Griffiths...y otros muchos.

Fue docente y rector de la Facultad de Teología Pontificia y Civil

Pues sí. Como rector estuve dos períodos; como docente, en total, 27 años. Comencé recién llegadito de Roma. Enseñé primero Derecho Canónico, después Moral y Pastoral. 


\section{$Y$ también en este tiempo tuvo que ir al CELAM}

Sí. Yo trabajaba en vocaciones y me tocó asesorar y acompañar a los obispos, primero en Medellín y después en Puebla.

\section{Creo que también pudo estar en el Concilio Vaticano II}

Cuando estaba en Roma me tocó participar en dos sesiones del Concilio Vaticano II, desde dentro, llevando papeles es verdad, pero la experiencia de vivirlas adentro eso es único también y doy por ello muchas gracias al Señor.

\section{¿Con qué obispo tuvo que trabajar o estuvo cerca en el Concilio?}

Conocí a muchos porque me tocaba ayudarles y facilitar que dialogasen entre sí. Recuerdo como anécdota a monseñor Corripio, arzobispo de México, que en paz descanse. Cuando comenzó una de las sesiones, entraron unas morenas bailando, llevando el Evangelio como entronización para dar inicio a las oraciones de las mañanas; y el obispo Corripio me dice: «esto es lo que nos falta en nuestra liturgia, ponerle más vida, más ritmo y más color». La verdad es que se me grabó.

Monseñor, la experiencia del Concilio fue algo tan grande, que me gustaría que nos trasmitiese para todos la gracia tan grande de momento tan singular, histórico para la Iglesia contemporánea. ¿Qué es lo que salió de ahi? ¿Qué espiritu se vivió?

La primera sesión fue un caos, nadie tenía experiencia de concilio. En un momento determinado hicieron entrar a monseñor Caringhi, que sí tenía experiencia de concilio y que contaba ciento tres años, del brazo de 
monseñor Alcides Mendoza, que tenía 31 años, nada más. El obispo más viejo y el obispo más joven del mundo.

\section{Juan XXIII}

Sí

Conduciendo...

Maravilloso Juan XXIII

\section{Beato Juan XXIII}

Y un incidente del Concilio que fue muy curioso lo resolvió Juan XXIII, con esa mentalidad pragmática que tenía él. El estrado de los cardenales contaba con butacas rojas y a los patriarcas los colocaron con los obispos, pero ellos se revelaron; dijeron: «somos la institución más antigua de la Iglesia y, por lo tanto, merecemos un sitio mejor. Nos vamos». Al día siguiente debajo de la estatua de san Pedro apareció una mesa larga con un mantel de tercio pelo rojo y el sitio para los patriarcas. Y es verdad; es la institución más antigua de la Iglesia; más que los cardenales. ¿Y cómo solucionó el problema Juan XXIII? Los nombró a todos cardenales y solucionado el problema. Después eso de cardenales, diáconos, presbíteros... dijo: «No, todo cardenal que no lo es, se ordena de obispo" y hemos visto las excepciones que han habido después, durante el gobierno de Juan Pablo II, los que no quisieron recibir el episcopado.

Pero la primera sesión fue tormentosa. Cuando terminó, parecía que no continuaba el Concilio, fue un ambiente de decepción. Luego hicieron cardenal al arzobispo Landázuri y me tocó estar de su secretario. La noche anterior comimos con don Pascuale y el cardenal Montini, y cenamos en un restaurante de Villa Medulana, al cardenal Montini se le veía un hombre con una tensión muy fuerte; lo tenía sentado frente a mí, precisamente. 


\section{Futuro Paulo VI}

Sí, como que se sospechaba ya. Lo que a mí me llamó la atención fue que lo vi entrar al cónclave y me tocó verlo de frente porque estaba con otro cardenal; caminaba rígido como el hombre que va al matadero. $\mathrm{Y}$ a la hora que sale el nombramiento - hay una ceremonia que se llama la primera adoración - el cardenal acompańado de sus secretarios se acerca y yo me acerco y vi un hombre brillante, vestido de blanco, radiante así, pero con una aureola de luz que me dejó impresionado, lo tengo grabado.

\section{La gracia ¿verdad?}

La gracia, lógicamente.

\section{Tanta oración de tanta gente}

Sí. Y, entonces, me acuerdo que él me dijo: «ruegue por mí, rece por mí». Le tocó un calvario al pobre, ciertamente.

\section{$Y$ vamos con el Concilio. ¿Cuándo se puede decir que entró?}

Y ese día, ese día, aquí viene el detalle. Así como en la embajada están los choferes esperando, se ponen a conversar entre ellos, que mi embajador dice esto y mi embajador dice lo otro. Yo estaba conversando con los otros secretarios y entonces la mayoría decía: «mi cardenal dice que este Concilio no sigue, aquí se acaba». Cuando el Papa dice: «el Concilio sigue adelante, nos reuniremos en la primavera nuevamente». Todos se quedaron sorprendidos; yo vi las caras del gran interrogante. La segunda sesión sí corrió mucho más suave y ya comenzaron a salir documentos y todas las cosas. Otro incidente del Concilio es que el cardenal de Boston se retiró porque no le permitían 
hablar en inglés, y yo no quería hablar latín. Se retiró y él ofreció poner un servicio de traducción simultánea.

\section{¿Para todos?}

Para todos, porque el Cardenal arzobispo de Boston Cushing manejaba mucho dinero. Ya a la mitad de esa sesión, yo me tuve que retirar por mis estudios. Para mí fue una experiencia muy rica, superada, sin embargo, después por las experiencias latinoamericanas de Medellín, Puebla, Santo Domingo y Aparecida.

¿Que es como una proyección de todo el espiritu de aggiornamiento o puesta al dia del Concilio, de esa renovación de toda la iglesia?

Quiero comentar una cosa que me llama la atención. Cada vez que doy charlas sobre este acontecimiento, se habla del Vaticano II como si se hablara del Concilio de Trento, se habla hoy de Medellín y de Puebla como algo del pasado y hoy día todo el mundo habla de Aparecida como si fuera el non plus ultra. Y si me pongo a revisar, como me gusta trabajar a mí un poco con concordancias y viendo lo que paso aquí y busco, me encuentro cosas en Puebla que son repetición, ahora con diferente lenguaje, en Aparecida. Y si encuentro algo que me llamó mucho la atención en esta proyección porque he estado trabajando este tema, es que Medellín menciona una sola vez la palabra santidad, Puebla la menciona más de cincuenta y tantas veces en diferentes normas, Santo Domingo un poco menos que Puebla y Aparecida la menciona más. Pero eso se lo debemos a un hombre extraordinario, a Juan Pablo II, que desde el primer momento habló de santidad y que en su documento testamento Novo Milenio Ineuntem, en el número treinta, nos dice qué es la pastoral de la santidad y eso cuántas veces me ha servido a mí. 
Yél mismo ha canonizado más que todos los papas juntos

Sí, y él mismo ha querido demostrarlo en su vida.

Más todavia, que es un santo. Pero volvamos, Monseñor, a su trayectoria...

Cuando en 1954 murió mi madre, yo pensé hacerme trapense, porque en realidad me gusta esa vida.

Pero por un tiempo

No, cuando hice mi retiro de diaconado en Canadá lo hice en la Abadía del Monasterio de Mistasini. Fui por seis días y me quedé diez, tuvo que venir el Obispo monseñor Pari a sacarme del monasterio porque yo ya no quería salir y me dijo: «tu obligación es regresar allá a tu tierra, trabajar y después pide permiso a tu Obispo». Cuando llegó el diaconado no me dejó ir a hacer retiro en Mistasini, pero ya cuando estuve en Roma de sacerdote fui a Tre Fontane y siempre estuve haciendo mi retiro con los Trapenses, porque los admiro profundamente.

Santo Toribio también tuvo...

Tentaciones

Por lo menos una. En el Museo Provincial de Salamanca hay un relieve que precisamente habla de la visión que tuvo de querer ser cisterciense cuando era universitario, pero parece que tuvo una revelación que el Señor le tenía reservado para otra misión.

Bueno, yo no tuve ninguna revelación, soy muy doméstico; les podría decir que soy muy humilde para tener revelaciones. 
Pero usted ha tenido esa actividad de manera muy contemplativa, me gustaria que nos hablase sobre todo por lo que yo le he conocido en Tacna y también el trabajo con los seminarios.

Bueno, visto que era un trapense frustrado. Y lo digo porque yo escribí a la muerte de mi madre una primera carta y no me la contestaron, una segunda carta y tampoco me la contestaron, una tercera carta en el mes de setiembre. En diciembre ya me llamaron para darme la noticia de que aceptara el episcopado.

Ya entendió lo que le gustaba

No, me acuerdo que le dije al que me lo anunció: «esto, ¿quién lo pide, usted?». «No» - me dice— «el señor Cardenal y el Santo Padre le piden que acepte el episcopado». «Si es así, por obediencia, le digo que sí». «No, puede pensarlo ocho días» — le dije— «no necesito pensarlo si ellos lo piden como usted lo dice; yo acepto», y acepté. Pero yo ya había comenzado mis ๙ิ planes con esta visión trapense y me dije: ¡bueno, vamos a trabajar un poco con los seminaristas! Y esa noche que yo llegué a mi casa, después de haber aceptado, llega la carta de la Trapa en que me dicen que había sido aceptado. Yo le escribí que llegaría un poquito tarde, con unas horas de retraso.

¿Y se quedó sin vida contemplativa?

Bueno, sí, pero como era director espiritual pude proyectarlo en los seminaristas y así preparamos el mes de espiritualidad e intentamos vivir una profunda vida de oración. Hicimos la experiencia del Ora et labora, muy benedictino. Los seminaristas vivían en un régimen de silencio, oración, seminario de espiritualidad, trabajo manual en la chacra y vivimos ahí, tan 
felices. Y yo, como director espiritual y como administrador. Desde entonces quedó establecido el mes de espiritualidad en el seminario; y cuando me fui a Tacna lo primero que hice fue poner el mes de espiritualidad con los seminaristas y pasarme el mes íntegro con ellos trabajando.

Pero alli, en Tacna, primero fue poner el seminario ¿no?

Efectivamente, allí no había seminario, estaban estudiando en Arequipa siete seminaristas para toda la diócesis. Y fue lo primero que me propuse. Cuando me nombraron a Tacna ¡oh desolación de desolaciones!, yo me dediqué a revisar un poco las estadísticas y me encontré que habían solo trece sacerdotes para toda la diócesis.

\section{$Y$ casi todos mayores de edad ¿no?}

El menor de cuarenta años y el mayor de ochenta. No había seminario. Tenía una casa episcopal que se caía de antigua. Y, ¡bueno!, lo único que quedaba era ponerse a rezar y manos a la obra. Yo tomé posesión el 18 de agosto y el 30 de agosto firmé mi primer decreto: La erección del seminario Misioneros San José en Tacna, ¿dónde?, en mi dormitorio, que era lo único que tenía, y que era la habitación más grande.

\section{Pero seguro que tenía muchos sueños}

No, puse ocho camas camarotes en mi dormitorio y yo me fui a dormir con otros dos misioneros a otro cuarto, el comedor servía al mismo tiempo para la hora de clases, la sala la dividí en dos. El dormitorio del obispo era el más grande y lo asignamos como capilla. Sacamos el comedor de donde estaba para situarlo más cerca de la cocina, donde estaba el comedorcito de diario. Y así comenzó el seminario. 


\section{En qué año estamos}

Estamos hablando del año 1991

\section{$Y$ ¿como obispo allá, cuántos años?}

Yo llegué en 1991 y ese mismo año abrí el seminario con ocho propedéuticos. Después, como no tenía seminario, los mandé a Colombia, al Seminario Misionario de la Ceja. Después de tres años habían como 22 seminaristas en la Ceja y el obispo me pidió que, por favor, ya no mandara más. Entonces comencé Filosofía en Tacna con los Eudistas y Teología en Lima; tenía todavía un grupo en Cusco, que fue una alternativa. En un momento determinado, se juntaron todos y comenzamos Teología, cambiamos a los Eudistas por personal propio y nos metimos también a construir nuestro propio seminario. Hoy ya está terminado y sirve a la diócesis desde el año 2001.

¿Cuántos sacerdotes se han ordenado hasta la fecha?

Yo he ordenado 38 sacerdotes en la diócesis, en total en mi vida episcopal tengo 52 sacerdotes ordenados, entre ellos y los religiosos que he ordenado. Dejé 42 seminaristas cuando salí de la diócesis.

$Y$ los primeros, en un gesto que a mi me conmovió, los envió fuera de la diócesis Exacto. Yo dije que había que ser generosos con el Señor. Si yo soy generoso con el Señor, el Señor va a ser más generoso todavía y decidí que a los dos primeros los iba a mandar a Bolivia, le escribí al Obispo ofreciéndolos, pero el Obispo no me contestaba. Y, un día, monseñor Martín, en una reunión de Cáritas, me dice: «Hugo, ¿ya mandaste los sacerdotes a Bolivia?». «No» —le 
digo- «no me ha contestado el Obispo». Y, entonces, me dijo: «¿por qué no me los das a mí para Pucallpa? Entonces le dije: «si tu carta me llega antes de la respuesta de Monseñor te los doy a ti». La respuesta me llegó por fax ese mismo día, y, bueno, promesa es promesa, hicimos una ceremonia muy linda y partieron los dos primeros rumbo a Pucallpa. Y allí hemos tenido la misión de Pucallpa durante diez años; después abrimos también la misión en el Vicariato de San Ramón por una petición expresa de Propaganda Fide.

A mi lo que más me ha impresionado de Tacna ha sido que toda la diócesis se ha convertido en diócesis, comenzando por el envio de los jóvenes ¿no es asi?

Sí, los jóvenes de confirmación.

Usted hablaba de que no le gustaba tener una diócesis con capillas de puertas cerradas...

Mira, eso comienza en Lima. Siendo obispo auxiliar de Lima me comencé a preocupar de que los seminaristas tuvieran dos meses de vacaciones o tres y comencé a establecer las misiones. Me acuerdo que del primer grupo que mandé a misiones, un seminarista me dice: «Monseñor, usted experimenta con nosotros, mes de espiritualidad, misiones, ¿qué más va a experimentar en el futuro con nosotros?». Le digo: "pero dense con una piedra en el pecho, ¡qué bueno que ustedes sirvan para ir creando cosas dentro de una diócesis!». Entonces, cuando llegué a Tacna lo primero que pensé fue en misiones; primero visité todas las parroquias para ver la realidad, 138.000 kilómetros en total.

Superó a Santo Toribio que recorrió 40,000 km., el perímetro para dar la vuelta al mundo 
Claro que no tenía la ventaja del carro...

\section{Por eso no tuvo ese accidente que tuvo usted}

Son alrededor de 1832 pueblos con nombre en los mapas, en la diócesis de Tacna, y 134.000 kilómetros cuadrados de extensión, el 60\% en la sierra. Una de las cosas que yo siento como más queridas, y eso que yo tenía pánico por ir a la sierra cuando era sacerdote.

\section{Limeño}

No, limeño no, peor todavía, chalaco, costeño. Cuando me mandaron allá, amé y amo intensamente la sierra. La gente se quejaba quizás que viajaba demasiado y que paraba en la sierra más que en la ciudad con ellos. Pero ellos no necesitaban y ahí me propuse la campaña con los jóvenes en las confirmaciones; les decía: «muchachos, les invito a una aventura, una aventura con mucha adrenalina, a visitar la realidad de esta diócesis a la que ustedes pertenecen». Iban 200, 180, 250 jóvenes a trabajar a los pueblos donde nunca llegaba un sacerdote y después la gente comenzó a pedirlos porque se acostumbró. Y de ahí surgieron tanto las vocaciones de chicos y chicas, tanto para las misiones y luego para las congregaciones religiosas. Fueron quince ańos de vida intensa en Tacna con mucha alegría y mucho gozo, y mucha pena también al retirarme.

Pero creo que San José también ha sido fuente y motivo de consuelo ¿no?

Bueno, San José fue para mí, cómo le puedo decir, el refugio; la casa episcopal se llama San José, los dos monasterios de Clausura se llaman también San José, la casa de Lima donde resido actualmente que antes era mía ahora es de la Diócesis, tiene el nombre de San José. Pues él siempre me ha ayudado 
y por eso en las tarjetas de mis invitaciones para mi ordenación sacerdotal y episcopal está presente. La imagen de San José que tenemos en nuestro seminario de Tacna es una figura muy tierna, me gusta mucho y la mandé hacer expresamente porque refleja lo que es San José y la ternura del niño, a su vez, con San José; por eso es que mi madre Santa Teresa decía que todo se lo pida, que el poderoso caballero es San José; me confié a él y a él le debo el seminario y lo poco que pude hacer en Tacna y también tengo que aprovechar la oportunidad — nunca me cansaré- de agradecer al monasterio de clausura, espero que sigan rezando todavía y, también ahora, estoy pidiendo para que recen por el seminario de Lurín.

Si dispone de tiempo todavía, me gustaría que nos contase en el último tramo del programa, ¿cómo vive un obispo emérito, entre comillas JUBILADO?

En esta parte de mi vida yo quiero comenzar dándole gracias a Dios, porque me ha permitido sentirme útil y cuando uno se siente útil vive, no me siento arrinconado, quizás podría estar arrinconado, pero no. En este momento enseño en la Universidad Católica Sedes Sapientiae porque me llamaron para coordinar el diplomado de Doctrina Social de la Iglesia, enseño Derecho Canónico en el Instituto de la Cruz.

\section{¿Dónde queda este instituto?}

Es de las Canonesas de la Cruz, a las que apoyo también celebrando la misa en su casa de Pueblo Libre. También soy director espiritual de algunos seminaristas en Lurín, doy algunos retiros para religiosas o sacerdotes y, además, tengo una obra de trabajo con sacerdotes que tienen dificultades para ayudarlos. 


\section{¿Ancianos o jubilados?}

No, no; sacerdotes jóvenes con los cuales vamos dialogando entre el psicólogo, psiquiatra y un servidor; vamos tratando de sacarlos adelante para ayudarlos.

Creo que ha tenido tiempo de entrar hasta animar a los jóvenes futbolistas de la selección, los JOTITAS, en algún momento.

Bueno sí, estuve con los jotitas para infundirles un poco el reconocimiento de todo el país, por lo que habían hecho para levantarnos el ánimo, y, bueno, tuve un rato de conversación con ellos y les planteé una dinámica de la unión, para que no fueran fósforos que se prenden solos, sino que fueran fósforos unidos que nadie los pudiese romper. Y bueno, ahí quedó la cosa y no me quiero meter más tampoco porque no me da el tiempo.

¿Y en el Consejo Nacional de Educación del que es miembro? Sin duda, que la educación es uno de los desafíos que tiene el Perú. El Papa recientemente hablaba de la emergencia educativa, mostrando su gran preocupación. ¿Y cómo lo ve usted? ¿Qué nos diría? Porque creo que necesitamos optimismo ante realidades como la PRUEBA de los docentes. Hay un ambiente muy derrotista por comprobar que están mal y sin saber dónde vamos.

Vamos a ver qué podemos hacer. Recién acabo de entrar. Yo lo decía desde el primer día que he estado con los del Consejo: «nos centramos en la instrucción escolar y no hablamos de educación». Y la educación va más allá que los colegios y los profesores de los colegios, la educación va más allá incluso que la universidad y hoy día el gran problema que existe es que la educación se recibe de manera informal, alrededor de cinco horas o más, 
a través de los medios de comunicación. Y, hoy día, hay que recuperar el aspecto cultural. Es verdad que hay una radio que está transmitiendo una serie de novelas, lo cual es un avance, pero son las novelas que le gustan a este autor, sin embargo todo lo que es la literatura peruana no se da a conocer y hay cosas muy buenas. Háblales a nuestros jóvenes de Ricardo Palma y ya no lo conocen o menciónales al sargento Canuto, Na Catita, el Caballero Carmelo, Tambores por Rancas, etc. Entonces yo hablé con el Ministro de Educación y me dijo: «yo quiero que usted figure allí en el Consejo para hablar sobre valores y cultura», y es eso lo que quiero hacer para ver en qué medida podemos influir un poco más, porque incluso hay programas en los que se puede llegar mucho más y a más gente, pero con un mensaje de valores.

Monseñor, vamos culminando. Una pregunta central: ¿Quién es Cristo para usted?

Esta mañana se lo decía a los participantes en la jornada que tenía con los de Cáritas. «Si el sacerdote no se enamora de Cristo, si usted no se enamora de su esposa y usted de su esposo están perdiendo el tiempo». La castidad no es problema de represión es problema de amor; quien no ama no es capaz de decirle «sí» al Señor y quien ama es capaz de decirle «sí» al Señor en medio de todas las dificultades y que podamos, todas las mañanas, decirle al Señor como Carlos de Foucauld: «Padre, me pongo en tus manos, haz de mí lo que quieras». Creo que es eso lo que necesitamos, estar disponibles como lo decía el Evangelio de hoy: "Quien me ve a Mí, ve al Padre y el espíritu que el Padre enviará los hará mis discípulos». En definitiva, dejarnos guiar por el Espíritu Santo, conformar nuestra voluntad a la de él. Esa es la manera de manifestar nuestro amor. 
Estamos a punto de iniciar, en muchos lugares, la gran misión continental de acuerdo a los postulados de Aparecida. Usted ha estado al frente también de la Iglesia del Perú como presidente de la Conferencia Episcopal Peruana; recuerdo que en aquellos momentos incluso le tocó sufrir muchísimo con sus hernias discales...

Acepté por obediencia

Pero supe que, incluso, en ese momento no dudó en conectarse con las autoridades politicas para evitar la promulgación de leyes contra de la vida. ¿Qué les diría a todos los católicos que están con una gran expectativa para servir a la Iglesia y al Perú en la vida pública?

Una de las cosas que quiero decirles es que tenemos que formar corazones decididos y algo más que corazones. En la reunión que tuve con todos los obispos en la Conferencia en enero dije que había que mandar a imprimir por lo menos ocho millones de Biblias o aunque sea Nuevos Testamentos, ya que no podemos conocer a Cristo si no hemos leído los cuatro evangelios; y si al pueblo le vamos a pedir alguna misión, tenemos que hacer una misión a partir de la Sagrada Escritura y a partir de los evangelios. Y, por eso, ¡ojala! que los fieles cristianos iniciaran una campaña de decir «yo regalo cinco Biblias, yo regalo diez» y se las llevamos al señor Cardenal y que él disponga de ellas ahora que viene la misión 
Monseñor, nos ha hablado de la santidad, las vocaciones, los jóvenes. Veo en usted una vida plena, que de la simple economía ha pasado a la economía de la salvación, que está sirviendo a la Iglesia, al Estado y a muchas entidades más. Usted es un referente para las generaciones jóvenes, ¿qué mensaje les daria a todos ellos?

Primero hay que dejarse seducir, quizá como el profeta decía «Me sedujiste, Señor». Estar disponibles a lo que el Señor quiera y el gran reto hoy es no ser masa, el gran reto de hoy es ser alguien y ese alguien solamente lo eres cuando tú descubres verdaderamente a Cristo e irradias ese Cristo a tu alrededor. Así como yo descubrí en Pablo VI ese hombre radiante, ese joven irradia cuando a su alrededor él siembra la semilla del amor de Cristo. 